\title{
HIGH-PERFORMANCE COMPUTING ENABLES SIMULATIONS TO TRANSFORM EDUCATION
}

\author{
Dan M. Davis \\ Information Sciences Institute \\ 4676 Admiralty Way, Ste 1001, USC \\ Marina del Rey CA 90292, U.S.A.
}

\author{
Thomas D. Gottschalk \\ Center for Advanced Computing Research \\ 1200 E California MS158-79, Caltech \\ Pasadena CA 91125, U.S.A.
}

\author{
Laurel K. Davis \\ Next Generation Leaders, Inc. \\ Post Office Box 2573 \\ Culver City, CA 90231, U.S.A.
}

\begin{abstract}
This paper presents the case that education in the $21^{\text {st }}$ Century can only measure up to national needs if technologies developed in the simulation community, further enhanced by the power of high performance computing, are harnessed to supplant traditional didactic instruction. The authors cite their professional experiences in simulation, high performance computing and pedagogical studies to support their thesis that this implementation is not only required, it is feasible, supportable and affordable. Surveying and reporting on work in computer-aided education, this paper will discuss the pedagogical imperatives for group learning, risk management and "hero teacher" surrogates, all being optimally delivered with entity level simulations of varying types. Further, experience and research is adduced to support the thesis that effective implementation of this level of simulation is enabled only by, and is largely dependent upon, high performance computing, especially by the ready utility and acceptable costs of Linux clusters.
\end{abstract}

\section{INTRODUCTION}

Education in this country is in extremis (Green et al. 2005). Stories of "hero teachers," while moving, make good anecdotes (Mathews 1989), but offer no rational paths to systemic solutions (Thernstrom and Thernstrom 2004). The failure to produce sufficient science and math personnel has driven the U.S. corporate world to seek competent technical help overseas (Friedman 2005). Efforts to find a new path to educational excellence have often gone astray (Stout 2000) and retrenchments to "old time" education are routinely critiqued (Mayer 2002). The classrooms are increasingly becoming unaccommodatingly heterogeneous in language skills, familial attitudes, literacy competence and family intellectual support.

This paper maintains that some of these issues can be best or, arguably, only ameliorated by the injection of simulation technology and high performance computing into the pedagogical mix for primary and secondary education.

The major conundrum of serving a diverse educational clientele remains how not to restrict the brightest while appropriately scaffolding learning for the novice, and at the same time providing support for development of the social, interactional and collaborative skills necessary to thrive in our institutions of learning and discovery. The fact that this conundrum is taxing for even the most talented and committed teachers leads the authors to conclude that innovative pedagogical delivery, including interactive simulation, is a necessary next step for the use of high-performance computing to enable education reform. The authors envision that such technological tools would not be the stuff of "enrichment" or luxury, as technology in the classroom has been thus far, but will become a cornerstone of the modern classroom, allowing live teachers to play to their strengths as facilitators with real relationships with the students, while parallel computing power grapples with the time and space constraints on instruction dictated by the limits of a singleinstructor, multiple-learner classroom environment..

The authors assert that High Performance Computing (HPC) has come of age (Fox et al. 1887). In the 1980s, visionary researchers at the California Institute of Technology began to postulate that the warnings advanced by Gene Amdahl (Amdahl 1967) about theoretical restrictions on using large numbers of processors could be overcome. This led to the development of parallel computers which were often referred to a Scalable Parallel Processors (SPPs). These ranged in size from the tens to hundreds of processors, all working in parallel on a single problem. Now thousands of processors in one computing platform are common (Dongarra et al. 2006)

Techniques were conceived, developed and implemented that indeed did prove many problems were practicably and effectively resolvable on "massively" parallel machines, attacked by using the power of this admittedly expensive configuration. Thomas Sterling and Don Becker advanced a lowcost approach to parallel computing, often called a Beowulf, which entailed the collecting of commercial off the shelf (COTS) personal computers and connecting them with a low cost inter-node communication network (Sterling et al. 1997). 
However, programming remains a non-trivial task for both of these platforms.

\subsection{Hrothgar Project}

The Hrothgar Project, named after the wise king in Beowulf, was an effort started by one of the authors (Gottschalk) the Center for Advanced Computing Research (CACR) at Caltech to explore the utility of highend (university research caliber) computers operating within high school curricula. A Beowulf Class PC cluster was selected as the initial platform. It was originally planned that the 4-processor "start-up" machine to later evolve into a 16-processor, 2 GFlops computer. Setting up the hardware was found to be the easy part. The harder part, by far, was finding the appropriate niche for the technology in a K-12 education environment. The exact characterization of this niche was by no means obvious.

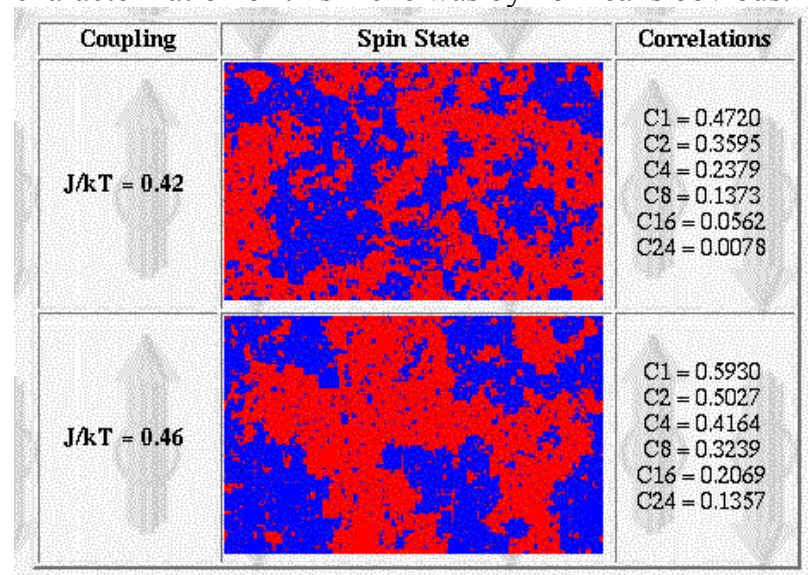

Figure 1: Student results obtained on ising model run

Hrothgar's first year of activities were seen as a "technology insertion experiment" based on three assumptions:

\section{Large-Scale Simulations Have Utility}

Access to realistic, large-scale simulations would be a useful tool for teachers in the sciences, social sciences and other disciplines. This enables modeling and analysis not feasible in standard learning environments and exposes students and teachers to advanced technology.

2. Simulations Must Come From "Research" In order to demonstrate both technology and research, the simulation projects run on the Beowulf machine should be adaptations of existing, research quality codes. Clearly, this cannot happen without active participation of the computational scientists who designed and implemented the original code.

3. Educators Must Direct Curricula Designs

Proper utilization of high performance computing in a classroom will require selective "focus- ing" of the science capabilities in the codes. This cannot be accomplished without active participation and pedagogical counsel of the educators throughout the design and implementation phases of each potential project.

However, leading edge technology cannot simply be left with the teaching staff with no further support." Educating the educators" on the importance of High Performance Computing was a significant secondary goal. But, the research scientists need "education" as well, since many of them had little experience with K-12 cognitive processes.

\subsection{Government Research in HPC Simulations}

Separate from education, there was a government need to optimize new high technology(Cebrowski and Garstka 1998) and simulate complex human functions (Ceranowicz et al. 2004). These often required environments in which human participants were critical (Sanne 1999). Analysts needed to conduct interactive experiments with entity-level simulations, using programs like Joint Semi-Automated Forces (JSAF) (Ceranowicz et al. 2002). The Joint Experimentation on Scalable Parallel Processors (JESPP) project is an example of the successful application of computational science and SPPs (Lucas and Davis 2003).

Implementing these simulations so that the user could involve humans augmented the user's ability to assess true impacts of a new system by including personnel and procedures. (Ben-Ari 1998) This led to several new methods of modeling individual human behavior (Hill 2000) and societal issues (Chaturvedi et al. 2000). As these all required significant additional compute power, software systems stressing efficient inter-node communications were necessary to achieve desired scalability (Gottschalk et al. 2005). These developments rested on the work that was led by Paul Messina at Caltech (Messina et al. 1997). The Synthetic Forces Express project (SF Express) began to explore the utility of SPPs as a solution to the communications bottlenecks that were then being experienced. More than 100,000 vehicles were simulated in 1998, using several different types of SPPs at nine separate sites, linked by a variety of widearea networks. (Brunett 1997)

This type of simulation frequently has a map visualization, as shown in Figure 2. The menu on the left allows the operator to lay down entities on the map, give them direction, modify their behaviors, and adjust their movements. Extensions into education are obvious. Being able to easily structure large-scale, distributed simulations would open a new vista for the educator trying to reach dispersed students at unpredictable schedules. The implemented independent-agent entities are fully capable of many autonomous operations, such as route finding, obstacle adjustment, known group behaviors and reactions to outside influences. A new defense sponsored program further allows the operator to vary the parameters of the independent agent entities, e.g. the top speed 
of a simulated vehicle, the ability of a pedestrian entity, the effects of a collision, etc. This technology would be easily transferable to the educators" "tool box." This capability should further enable the use of the best teachers in the nation. They could easily design and test educational modules of measurable efficacy and indefinite service life-spans.

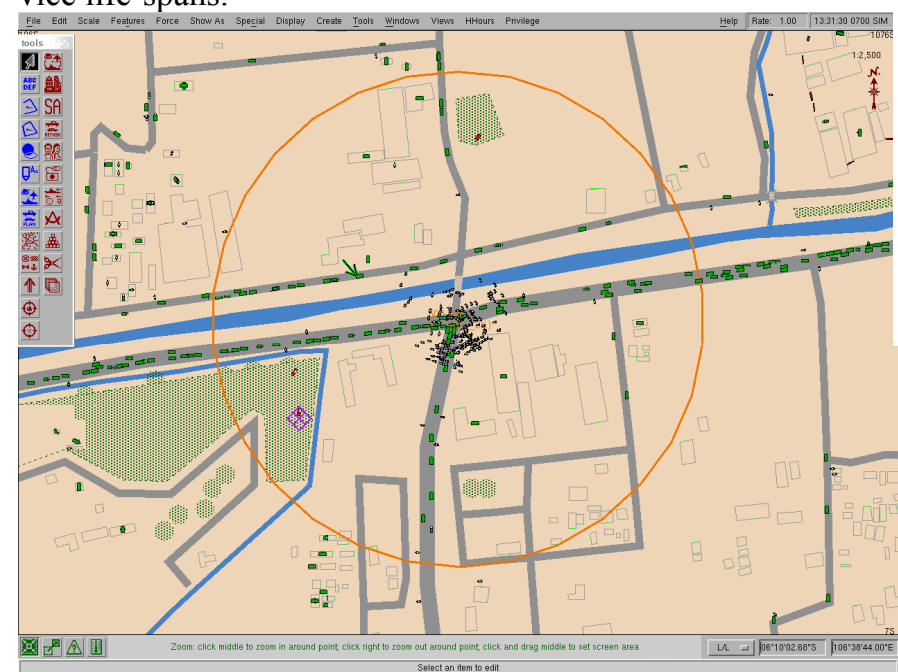

Figure 2: Map-like plan view display

A few workstations on a local area network (LAN) was found sufficient to support simulations of a few thousand entities in a typical JSAF run. A simple broadcast of all data to all nodes is sufficient. Each node discards data that is not of interest to it. The Run Time Infrastructure (RTI) controls this activity. When the simulation was of tens of thousands of entities using scores of PCs, broadcast was not sufficient. UDP multicast has proven to be a good solution to this issue, in lieu of the simple broadcast. In this case, each simulator receives only the data to which it has subscribed, i.e. in which it has a stated interest. This leaves enough compute capacity for data management and visualization, e.g. a three dimensional, rendered view of the urban area, such as shown in Figure 3.

\subsection{Current Large Scale Simulation}

Recent experiments within the Joint Forces Command's Experimentation (JFCOM) Directorate, J9, demonstrate the feasibility of simulation applications in a large field of play with fine-grained resolution. Simulating such spaces requires large computational resources, often distributed across multiple sites. The ongoing Joint Urban Operations (JUO) experiments utilize the JSAF application suite and RTI-s to scale to over 300 federates distributed across the continental United States and Hawaii (Ceranowicz 2002). The JUO exercise has shown the scalability of the JSAF/RTI-s infrastructure and the ability of interest-based, router-managed communication to serve over $1,500 \mathrm{hu}-$ man participants with ease.

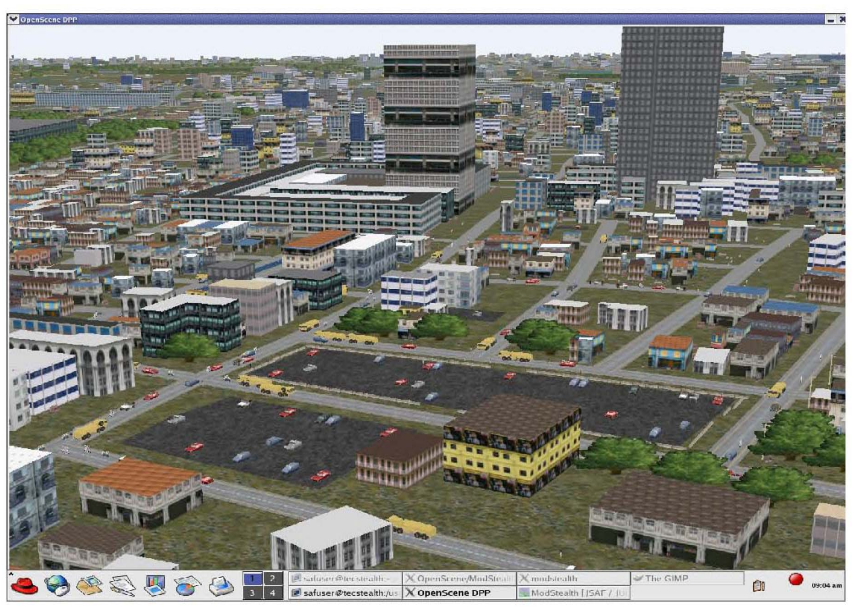

Figure 3: Simulated urban area

\section{EDUCATION AND TECHNOLOGY}

How can this HPC capability be used to resolve the educational conundrums mentioned above? The authors assert that HPC is needed. Current research in cognitive science and education indicates that, in order for meaningful learning to be usefully transferred to various settings, high-quality instruction must be integrated with frequent opportunities to:

1. apply abstract knowledge in multiple authentic contexts (Gick and Holyoak 1983; Cognition and Technology Group at Vanderbilt 1997; Bransford 1998),

2. receive feedback on the validity and success of the application (Bransford 2000), and

3 . re-engage in instruction with refined knowledge targets.

More often, the majority of learners work passively from a textbook, in a setting of diminished rigor (Bransford 2000) and rarely engage in the depth described above. Two of the major factors in the narrowness of the instructional approach in most classrooms are time and space. If teachers ideally wish to create instruction that is differentiated to meet the needs of each learner or group of learners, they must have much more time to assess, analyze and prepare students for engagement with a topic, and respond specifically enough to each learner's experience that the learner can gain meaning from the feedback. Two of the most important steps - in helping students learn meaningfully - reflection and integration with previously learned concepts - are the first to go when time is pressed. Once a teacher is aware of the various modes in which students learn best, the teacher may still be restricted in delivery; not enough chairs, books, spaces or screens to support group work with discussion that is not disruptive, not enough physical breathing room between students for concentration and crowd management, not enough room for manipulative or hands-on experiences that would cement the concept in students' minds. This mode is insufficient to yield the critical understanding that will enable them to actually use the knowledge in varied contexts. 
Continuing advances in HPC technology provide a welcome opportunity to engage learners in real-time authentic contexts most relevant to subject content and learning needs, with some larger measure of control over the time and space factors of group learning. Educators could accelerate the learning curve and raise the competency of students by providing immediate, repeated and user- or variable-influenced simulation experiences in which learners must synthesize and apply their developing content knowledge.

\section{COLLABORATIVE LEARNING}

There is good evidence that collaborative learning environments are an effective way to facilitate and intensify engagement with knowledge. An SPP-enhanced system would also increase the quality and frequency of feedback provided. Recent emergence of social networking technologies reflects the potential for improved engagement of students through use of high-quality virtual environments. This allow for access to "distributed cognition," (Vye et al. 1998) and it enables problem-solving and cognitive development in ways that single-student exercises may not (Evans 1989; Newstead and Evans 1995; Kobayashi 1994). The participation of experts and novices in tandem in complex contexts, via collaborative learning environments, provides opportunities for conflict, selfexplanation (attempts by experts to convey knowledge to novices) and internalization (absorption of knowledge by novices exposed to experts). These serve to deepen understanding, expose misconceptions, and lower affective filters that may inhibit learning (Dillenbourg and Schneider 1994).

Collaborative learning environments have been criticized as not always being as effective as knowledgecentered learning because subject matter experts with whom the students would collaborate are not necessarily sufficiently knowledgeable about strategies for facilitating novice understanding (Shulman 1986), clearly confirmation of the Hrothgar insights above. Collaborative learning using scalable computing can help to address this liability in collaborative learning. HPC can provide the communications bandwidth and computational power to manipulate the variables of the learning contexts themselves and the different capabilities of the learners in the group (Davis and Davis 2003). An environment thus created would be modifiable from a content perspective and could be modified both by expert students and skilled instructors to meet the pedagogical needs of all learners in the group.

Education necessarily must be a life-long process. Most believe that everyone, regardless of background or educational level, should be afforded unfettered and continuous access to the best and most inclusive educational programs of which they are capable. The authors assert that HPC has provided the capability of robust distance learning to allow the learning process, as conveyed by the best teachers, to be amplified and proliferated, such that everyone can learn to his or her own capacity and motivation. Without HPC capabilities, only a few could experience the best in education, with the concomitant unacceptably poor results (Thernstrom \& Thernstrom 2004).

\section{EXPERIENCE WITH HPC ON TRANS- CONTINENTAL ENVIRONMENT}

One of the great strengths of the JFCOM experimental design is its use of distributed assets and service to dispersed users. The experiments themselves are housed and controlled by the JFCOM out of its experimental bay near Suffolk, Virginia. Environments and data are managed remotely out of Fort Belvoir in Northern Virginia. The civilian "culture" entities are laid down and managed by a team a continent away in San Diego, at the SPAWAR center on Point Loma. The two 128 node, 256 processor Linux clusters that are provided by the HPCMP, are located in Maui at the Maui High Performance Computing Center (MHPCC) and at Wright Patterson Air Force Base at the Aeronautical Systems Center Major Shared Resource Center (ASC-MSRC) in Ohio.

Communications between the sites are provided by the Defense Research and Engineering Network (DREN). The Linux operating system is common across the net (usually Fedora, but also Red Hat Enterprise) and most of the programs are written in $\mathrm{C}++$, with a smattering of Java.

Note that there are geographical separation issues, Maui being on the order of five thousand miles from Suffolk, as indicated in the notional diagram in Figure 4. Fortunately, speed of light latencies alone are not readily detected by humans and is easily tolerated by both operators and participants. HPC distributed education may rely more heavily upon the distributed game experience, where an ongoing action may be joined or left at the discretion of the participant. Additionally, maintenance and help-desk personnel could rotate around the world, a la "The World is Flat" (Friedman, 2003).

However, the previous experience in trans-continental simulation will be critical in a Nation-wide distance educational effort, as such an initiative might well be literally worldwide. While efficient routing reduces latencies, naturally the speed-of-light-latency is a phenomenon with which future user will have to contend.

This system was used by JFCOM to assess future strategies, future capabilities, and future personnel needs. Being able to realistically simulate a battlespace, populate it with intelligent agent entities and involve humans-in-the-loop, not only acted as an evaluation tool, but also provided training, and in an oblique sort of way, education. One Lieutenant General remarked that one of the experiments was his only career opportunity to command a brigade in combat, an experience that was more educational in its general insights, than training in its specific skill improvements. 


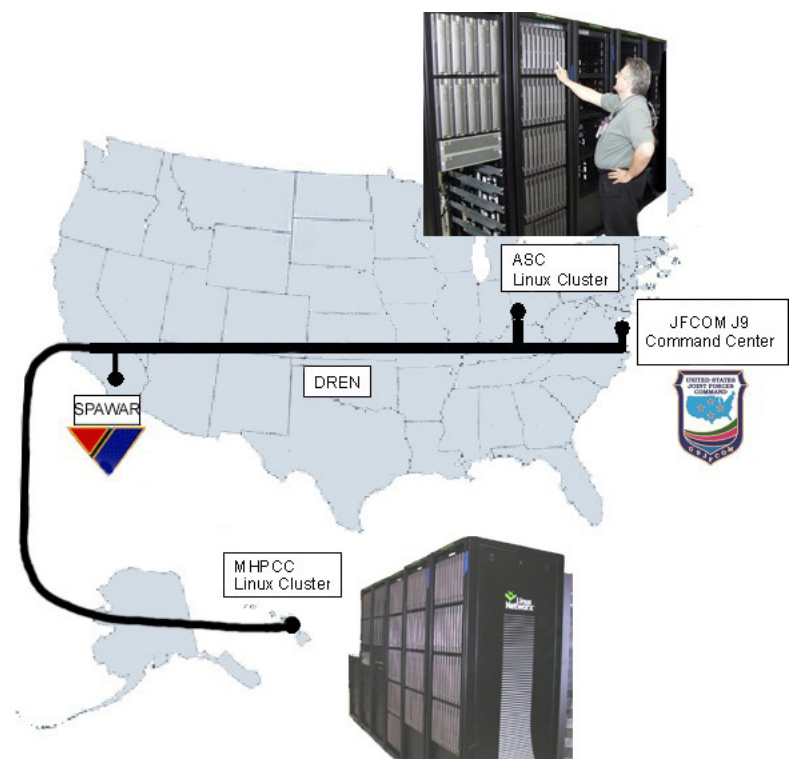

Figure 4: Notional simulation net map

\section{VISIONS OF POTENTIAL OUTCOMES (WITH AND WITHOUT LARGE-SCALE TECHNOLOGY)}

\subsection{Needed Educational Enhancements}

There are many enhancements that are needed because the students are not centrally located, they bring different cultural backgrounds, are accustomed to widely varying sets of standards, approaches and biases. Most of these can be overcome by really good teachers, who do not need simulation to obtain the needed improvements. However, there are clearly not enough of these teachers to go around.(Thernstrom and Thernstrom 2004). The authors posit, and to some degree have observed, that pedagogically sophisticated, interactive simulations can make up for this scarcity by extending the reach of good teaching..

USC has a very effective Distance Education Network in which live educators provide education for students, world wide. This need was particularly evident in the defense industry. New visualization techniques and interactive computer instruction show promise for opening up education to wider populations. Researchers at USC (Johnson and Beale 2003) use avatars for teaching. In an earlier paper, two of the authors (Davis \& Davis 2003) advanced the use of short MPEG clips instead of animated avatars. JFCOM's experience with HPC has shown that it can extend the span and reach of existing simulations. A similar advantage is seen in using expansive arrays of appropriate MPEG clips, all interactively initiated as the simulation aided education program calls for them. As the "human component" of teaching and learning is so critical, the use of avatars, even as they become more realistic, can have a negative effect.

As noted above, experience indicates that the learner becomes more involved if exposed to an interactive environment. There is evidence that true interactivity, both in the interface and in the presentation methodology, will further enhance learning and retention. The key question in this area is the efficacy of the combination of virtual environments and interactive teaching techniques in enhancing focused education. Two other critical issues are the architecture of the compute/networking assets needed to economically serve such a program and the impact such a program might have on students' achievement and attitudes. (Davis and Davis 2006).

Content generation is another area that is clearly amenable to HPC. All of the standard text books in the country have been converted to electronic media. The problem comes from transferring the vast amount of this data into optimal interactive configurations. The authors can envision the use of HPC to input the data, analyzed important parts using some of the natural language research at ISI, develop interactive modules and then test them with subject matter experts. HPC and distributed data management should also enable assessment of the systems, progress for the students and areas in need of supplemental instruction.

\subsection{Conceptual Development of Educational System}

Figure 5 is a flow chart of a concept interaction program that is part of an educational system. Clearly HPC power would be needed for the simulation containing such a module.

\subsection{Real Experience}

The experience of the users with trans-continentally distributed High Performance Computing has been good and that experience supports further development across this discipline (Wagenbreth et al. 2005). The stability and the utility of the large Linux clusters in Ohio and on Maui have elicited the unsolicited admiration of both the technical and the analytical professionals using the system. These experiments required the large-scale simulations on the clusters in Ohio and on Maui to operated reliably for weeks at a time, They were further required to collect data at a rate greater than 10 GB per hour (Yao et al. 2005). Not using this capability to meet the needs of education in the U.S. seems imprudent.

\subsection{Educational Implementations Suggested}

While previous large-scale simulation use has been focused on analytical purposes, the major thrust of this paper is education. The authors assert all of the open issues in education are, to some degree, amenable to solutions via HPC Some adaptation must be forthcoming, but that is within current technical capabilities in the simulation and HPC communities 


\section{Davis, Gottschalk and Davis}

(Lucas and Davis 2003). The authors do not suggest this will be a trivial process, but they hold that previous experience has shown that technology and intellectual capabilities are available, should they be directed to educational pursuits rather than defense analyses. This should allow the leveraging of the best teachers, the improvement of multi-cultural approaches and the optimization of exploitation of the "teachable moment." Details in the earlier implementations can be found in a paper by two of the authors and others (Davis et al. 2005)

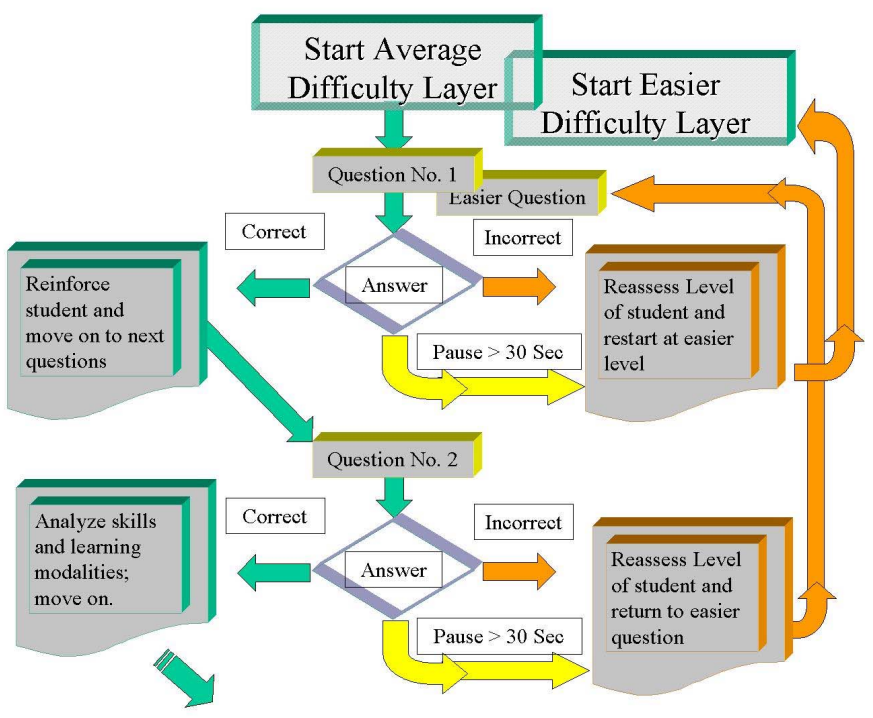

Figure 5: An early flow chart showing a putative design for an instructional module

\section{Conclusion}

The authors started from what they consider to be a virtually unassailable set of premises:

- Evaluation and training have benefited from simulations using high performance computing

- $\quad$ Education needs newly developed capabilities to keep up with modern demands

- Users, educational assets, and computing systems are often dispersed geographically

- Technology is available to deliver HPC power to educational systems

Another insight, flowing from the these, was that the experience and insights from the High Energy Physics community were more germane than were the commercial transaction-processing programs or the Internet recreational data-search designs. The reason for this is assumed to be the closer relation to the types of data, the technical literacy of the users, the more uniform access to highbandwidth, and the lack of the need for elaborate interuser security, but very high external security.
A third insight is that working with open-source, public licensed software has many advantages for the developer. The Linux community is active and involved. Source code is available for scrutiny, modification, and implementation. While the authors recognize the value added by major commercial vendors and their support staffs, the JESPP experience indicates that open source software should be seriously considered. (Graham et al. 2004)

While the great bulk of the code to be developed is easily within the capabilities of journeymen programmers, the overall design can be fatally crippled if it is not optimized for parallel processing. It is the authors' experience that, at this time, there is no substitute for absolutely world-class parallel architects. Finding creative and experienced parallel programming personnel is a sine qua non. It is a variant of the facts earlier articulated by Fred Brooks, (Brooks 1995) who emphasized the value of extraordinary programmers. He thought any one of them were worth as much as ten other programmers. A prudent implementer of a distributed educational system would be ill-advised to proceed without an experienced and successful parallel architect, one with a proven track-record of innovation on computers of the appropriate scale.

High Performance Computing had brought the simulation community new capabilities, which then yielded incredible amounts of new information, leading to the need for large scale and sophisticated data analysis, for which HPC facilities are optimized. Education is in dire need of all of these, especially considering the constraints on the population. The combination of careful planning and openness to others skills are required for success in the provision of Education to the Nation.

\section{ACKNOWLEDGMENTS}

The authors wish to acknowledge the members of the ISI JESPP team who have contributed to this paper through their efforts and their intellectual stimulation. Much of the success reported here came from the Joint Experimentation on Scalable Parallel Processor project, initiated, directed and funded by the Joint Forces Command and to a very large degree conducted on the compute assets of the Maui High performance Computing Center, ASC-MSRC at Wright Patterson Air Force Base and other members of the High Performance Computing Modernization Program. Some of this material is based on research sponsored by the Air Force Research Laboratory under agreement number FA8750-05-2-0204. The U.S. Government is authorized to reproduce and distribute reprints for Governmental purposes notwithstanding any copyright notation thereon. The views and conclusions contained herein are those of the authors and should not be interpreted as necessarily representing the official policies or endorsements, either expressed or implied, of the Air Force Research Laboratory or the U.S. Government. 


\section{REFERENCES}

Amdahl, G.M. 1967. Validity of the single-processor approach to achieving large scale computing capabilities. In AFIPS Conference Proceedings 30:483-485, AFIPS Press, Reston, Va.

Ben-Ari, E. 1998. Mastering Soldiers: Conflict, Emotions and the Enemy in an Israeli Military Unit. New Directions in Anthropology 10. Oxford: Berghahn Books.

Bransford, J.D., B. Barron, D. Schwartz, N.J. Vye, L. Zech and Vanderbilt Cognition and Technology Group. 1998. Designs for environments that invite and sustain mathematical thinking. In Symbolizing, Communicating and Mathematizing:Perspectives on Discourse, Tools and Instructional Design, P.Cobb, ed. Mahwah, NJ: Erlbaum.

Bransford, J.D., A.L. Brown, and R.R. Cocking, eds. 2000. Learning and Transfer. In How People Learn: Brain, Mind, Experience, and School, Washington, D.C.: National Academy Press.

Brooks, F. 1995, The Mythical Man-Month: Essays on Software Engineering, Addison Wesley, New York

Brunett, S., Davis, D., Gottschalk, T., and P. Messina 1998. Implementing distributed synthetic forces simulations in metacomputing environments. Seventh Heterogeneous Computing Workshop, Orlando, Florida

Cebrowski, A.K. and J.J Garstka 1998. Network Centric Warfare: Its Origin and Future, In Naval Institute Proceedings, 124/1, 28-35.

Ceranowicz, A., M. Torpey, W. Hellfinstine, J. Evans and J. Hines. 2002. Reflections on building the joint experimental federation. In Proceedings of the Interservice/Industry Training, Simulation and Education Conference, Orlando, FL.

Ceranowicz, A., M. Torpey, 2004. Modeling human behaviors. In Proceedings of the Interservice/Industry Training, Simulation and Education Conference, Orlando, FL.

Chaturvedi, A., M. Gupta, S. Mehta, and W. Yue, 2000. Agent-based simulation approach to information warfare in the seas environment. In 33rd Annual Hawaii International Conference on System Sciences HICSS33, 4-7 January.

Cognition and Technology Group at Vanderbilt. 1997, The Jasper Project: Lessons in Curriculum, Assessment and Professional Development. Mahwah, NJ: Erlbaum.

Davis, D.M. and L.K Davis,. 2003. An interactiveteaching virtual museum: implementation of a new digital one-on-one pedagogy for K-6 students from a multi-cultural society, Unpublished Whitepaper, Available via
<wWw.isi.edu/ ddavis/DanzFiles/K12Educ/IVM/IVM Paper2Col.doc >

Davis, D.M. and L.K. Davis 2004. Educational extensions of large-scale simulations enabled by high performance computing. In Proceedings of the Interservice / Industry Training, Simulation and Education Conference, Orlando, FL

Davis, D.M., R. Lucas, P. Amburn, and T. Gottschalk, 2005. Joint experimentation on scalable parallel processors. ITEA Journal of Test and Evaluation, 26(2), Fairfax, Virginia.

Dillenbourg, P., and D. Schneider. 1994. Collaborative learning in the internet. In Proceedings, Fourth International Conference on Computer-Assisted Instruction, Taiwan. S10-6 to S10-13.

Dongarra, J., H. Meuer, and E. Strohmaier. 2006. TOP500 Supercomputer Sites 22th Edition. In Proceedings, SC06, Seattle, Washington, down loaded <http: / / www.top500.org/list/2005/11/10 $0>$

Evans, J. St. B.T. 1989. Bias in human reasoning, Hillsdale, NJ: Erlbaum.

Fox, G., P.C. Messina and R. Williams. 1994. Parallel Computing Works. San Francisco: Morgan Kaufman Publishers

Friedman, $\mathrm{T}$ 2005. The world is flat: a brief history of the twenty-first century. New York: Farrar, Straus and Giroux.

Gick, M.L. and K.J. Holyoak. 1983. Schema introduction and analogical transfer. Cognitive Psychology 15:1-38.

Gottschalk, T. and P. Amburn,. 2005. Extending the meshrouter framework for distributed simulations. In Proceedings of the Interservice / Industry Training, Simulation and Education Conference, Orlando, FL.

Graham, S., M. Snir, , and C. Patterson., Editors 2004. Getting up to speed, the future of supercomputing. The National Academy Press, Washington, D.C.

Graebener, R., G. Rafuse, R. Miller, and K.-T. Yao. 2003 The road to successful joint experimentation starts at the data collection trail. In Proceedings of the Interservice / Industry Training, Simulation and Education Conference, Orlando, FL.

Green, J.P., G. Foster, and G.A. Winters 2005. Education myths. Lanham Maryland: Rowman and Littlefield Publishers

Johnson, L. and C. Beale. 2003. Iterative evaluation of intelligent game in language education, In Proceedings of the Artificial Intelligence in Education, Sydney, Australia

Kobayashi, Y. 1994. Conceptual acquisition and change through social interaction, Human Development 37:233241.

Lucas, R. and D. Davis. 2004. Joint experimentation in scalable parallel processors. Proceedings of the Interservice / Industry Training, Simulation and Education Conference, Orlando, FL. 
Mathews, J. 1989, Escalante: The best teacher in america. New York: Henry Holt and Company

Mayer, R.E. 2002. Rote versus meaningful Learning, Theory into Practice 41(4): 226-232

Messina, P., S. Brunett, D. Curkendall, D. Davis, T. Gottschalk, and H. Seigel. 1997. Distributed interactive simulation for synthetic forces. In the Proceedings of the 11th International Parallel Processing Symposium, Geneva, Switzerland

Moore, J. 1998. Education versus training. Journal of Chemical Education 75(2).

Newstead, S.E., and J. St. B. T. Evans, eds. 1995. Perspectives on thinking and reasoning: Essays in Honour of Peter Wason. Hillsdale, NJ: Erlbaum.

Sanne, J. 1999. Creating safety in air traffic control. unpublished doctoral dissertation, Institute of Tema Research, Linköping University, S-581 83 Linköping, Sweden.

Shulman, L. 1986. Those who understand: Knowledge growth in teaching. Educational Researcher 152:414.

Sterling, T., D.J. Becker, J., Salmon, \& D.F. Savarese. 1999. how to build a beowulf a guide to the implementation and application of PC clusters. Cambridge, MA: MIT Press,

Stout, M. 2000. The feel-good curriculum: the dumbing down of america's kids in the name of self-esteem. Cambridge MA: Da Capo Press

Thernstrom, A., and S. Thernstrom 2004. No excuses: closing the racial gap in learning. Simon and Schuster, New York, New York

Vye, N.J., S.R. Goldman, C. Hmelo, J.F. Voss, S. Williams, and Cognition and Technology Group at Vanderbilt. 1998. Complex mathematical problem solving by individuals and dyads. Cognition and Instruction 15(4).

Wagenbreth, G., D. Davis, T. Gottschalk, R. Lucas and K-T. Yao. 2005. publication pending, Operational experience, distributed simulations, data management and analysis, Proceedings of the 2005 Winter Simulation Conference, Orlando, FL.

Yao, K-T. and G. Wagenbreth. 2005. publication pending. Simulation data grid: joint experimentation data management and analysis. In Proceedings of the Interservice / Industry Training, Simulation and Education Conference, Orlando, FL.

\section{AUTHOR BIGRAPHIES}

Dan M. Davis is the Director, JESPP Project, Information Sciences Institute (ISI), University of Southern California, and has long been active in large-scale distributed simulations for the DoD. While he was the Assistant Director of the Center for Advanced Computing Research at Caltech, he managed Synthetic Forces Express, a major simulation project. He received a B.A. and a J.D., both from the University of Colorado in Boulder. His web page can be found via <www.isi.edu/ ddavis>.

Thomas D. Gottschalk is a Member of the Professional Staff, a Senior Research Scientist at the Center for Advanced Computing Research (CACR), and Lecturer in Physics all at the California Institute of Technology. He has worked at CACR for more than a decade advancing the use of massive parallel computers for simulation. His instructional duties include Statistics and Experimental Design for Caltech Physics Graduate students. He received a B.S. in Physics from Michigan State University and a Ph.D. in Theoretical Physics from the University of Wisconsin. His web page can be found via <oscar.cacr.caltech. edu/ tdg/Documents>.

Laurel K. Davis is the Director of Next Generation Leaders, Inc., an independent educational consulting and research organization in Culver City, California. She is an experienced classroom educator who has served in several public schools in the Los Angeles basin. Her current activities include teacher training, consulting on the transition from one school environment to another, creation of materials to address nonacademic skills. She has developed and fielded several programs on leadership training and assessment. She received a B.A. in Communications and a M.Ed., both from the University of California, Los Angeles. Her web page can be found via <www. appletreeservices.com> 